\title{
Bio-Nanocomposites: Parepartion Technology and Applications
}

\author{
Fadhil K. Farhan', Nura Anwer Abdulzahara², Muhammad AL-Jobori ${ }^{3}$ \\ ${ }^{1}$ Assistant Professor, ${ }^{2}$ Research Scholar, ${ }^{3}$ Research Scholar, Department of Medical Physics, \\ College of Science, University of Karkh for Science, Baghdad, Iraq
}

\begin{abstract}
In this paper, combinations of a ceramic mixture with a polymer were developed to be used as a substitute for damaged bones or teeth. Overlays were prepared using the manual mixing method, followed by the use of ultrasound technology to ensure uniform distribution of the powder within the polymer. The polymer (PMMA) is supported with a ceramic powder $(\mathrm{HAMgO})$ prepared using an effective mechanical mixing method. Where the percentages were used for consolidation, starting from $(1 \%-4 \%)$. The results of the tests showed mechanical corrosion or the so-called wear and tear of a significant improvement for the reinforced polymeric compounds as the corrosion rate decreased to less than half at $4 \%$. Likewise, the results of the particle hardness examination showed a successive increase in the percentages compared to the polymer base material. The results of the durability of compressibility and the Yunk coefficient showed a direct increase with the increase in the percentages of the added ceramic powder. The results were interpreted using the scanning electron microscope and by relying on the density values approved from the results of the exercise.
\end{abstract}

Keyword: Nano-composites, polymer, PMMA, HAMgO, Compression Strength, Young Modulus.

\section{Introduction}

Polymeric composites have unique properties that qualify them to work in all fields, including industrial, medical and engineering, in addition to their use in military applications and in the manufacture of spacecraft ${ }^{[1,2]}$. Many researchers in this field were interested recently in this century in developing and producing polymeric-based compositions that act as materials that have the ability to withstand various mechanical stresses and have the ability to operate in harsh environmental conditions ${ }^{[3,4]}$. In light of this, many researchers were able to prepare polymeric nanoparticles that are used in bone and skeletal alternatives as well as used in the manufacture of teeth and their permanent fillings ${ }^{[5,6]}$. These prepared compounds underwent

\footnotetext{
Corresponding Author:

Fadhil K. Farhan

Department of Medical Physics, College of Science, University of Karkh for Science, Baghdad, Iraq e-mail: fadfarh9@gmail.com
}

high physical and mechanical conditions and showed great success in tolerating scratching and wear and resistance to fracture compression ${ }^{[7,8]}$. The polymers are histologically compatible with the organism are the most important characteristics in the formation of nanocomposites in this field and the most important medical polymers are (PLA, PMMA, HDPE, PVA, as well as biochemical materials are one of the pillars of the preparation of polymeric compounds for medical compensation use, such as $\mathrm{Al}_{2} \mathrm{O}, \mathrm{ZrO}_{2}, \mathrm{TiO}_{2}, \mathrm{CaO}, \mathrm{HA}$, $\mathrm{MgO}^{[9,10,11]}$. These compounds have specific properties that have the ability to withstand mechanical stresses and have the ability to resist bacteria and fungi. Most ceramic materials are materials compatible with body tissue and bonding, especially if they are in the nanoscale ${ }^{[12,13]}$. Many researchers studied at AH in the field where the researcher Fadhil K. Farhan and et al. Prepared polymer compounds supported with binary ceramic powder from and obtained advanced results in improving mechanical properties $^{[14]}$. The aim of the research is to manufacture Nano molecules based on a polymer supported by a resistant bi-ceramic market Wearing and working in exceptional conditions and in various forms. 
Materials and preparation of nanocomposites: The materials were prepared first after they were diagnosed and their ability to work in this field was determined as the polymer was purchased and it is in two parts the first is a liquid called the monomer chloroform and the second part which is the powder imported from the United Arab Emirates and with regard to ceramic powders it has been imported from the US states with a size of 20 nanometers and a purity of 99.998. The overlays were prepared using liquid mixing and ultrasound technology for 10 minutes to ensure a homogeneous distribution between the polymer and the binary powder. Then the models were formed according to the measurements approved in the examination.

Practical part: The PIN-ON- DISC system was used to calculate the sliding wear and tear wear rate of the compounds. Models were created with dimensions of $1 \mathrm{~cm}$ in diameter and $3 \mathrm{~cm}$ in length. Using the following equations, the final wear rate ${ }^{[15]}$. Was calculated:

$\mathrm{W}_{\mathrm{r}}=\Delta \mathrm{m} / \mathrm{S}_{\mathrm{D}} \ldots \ldots \ldots \ldots \ldots$ Wear rate $(\mathrm{g} / \mathrm{cm})$

$\Delta \mathrm{m}=\mathrm{m}_{1}-\mathrm{m}_{2} \ldots \ldots \ldots \ldots \ldots$ Wear loss $(\mathrm{g})$

$\mathrm{S}_{\mathrm{D}}=\pi$. N.D.T ............. Sliding distance $(\mathrm{m})$

$\mathrm{V}_{\mathrm{S}}=\pi . \mathrm{N} . \mathrm{D} / 60 \ldots \ldots \ldots \ldots . . .$. Sliding velocity $(\mathrm{m} / \mathrm{s})$

\section{Where:}

$\mathrm{N}: 2950$ (rive/min)

D: Routing distance $(\mathrm{m})=0.06 \mathrm{~m}$

T: Sliding time (min)

$\mathrm{W}_{\mathrm{v}}=\mathrm{W}_{\mathrm{r} /} \rho \ldots \ldots \ldots \ldots . . .$. Volume Wear

$W_{\text {coeff }}=W_{v} \cdot H_{V} / L . S_{D} \ldots \ldots \ldots \ldots \ldots$ Coefficient Wear

\section{Where:}

$\rho:$ Experimental density $(\mathrm{g} / \mathrm{cc})$

$\mathrm{H}_{\mathrm{V}}$ : Number Hardiness (MPa)

With regard to density, the Archimedes method was used to calculate the density of nanocomposites as well as the dimensional method to ensure the accuracy of the calculation. Vickers hardness device was also used to calculate the surface micro hardness of the superposition's where the results were recorded directly from the system in mica units and using a time of 20 seconds and a force of 0.5 Newton where the equation was used:

$$
\mathrm{Hv}=1875 \mathrm{p} \backslash \mathrm{d}^{2}(\mathrm{MPa})
$$

With regard to the compression test, the results were obtained by the examination system, called the universal machine, where the models were formatted as cylinders with dimensions of $2 \mathrm{~cm} \times 2 \mathrm{~cm}$

\section{Results and Discussion}

Physical Properties Results: Table No. (1) And Figure (1) show a summary of the practical results of the physical properties that were performed for the prepared models, where the values of the practical intensity that were calculated by the Archimedes method and also were confirmed using the dimensional method. The results showed a significant improvement in the values of practical density with a direct increase with the percentage of additives. The reason is due to the closing of pores and the stacking of particles between the components of the mixed materials. The other reason is due to the high density of the additive and to the high surface area and the nano-scale of it. This is illustrated in Figure 1 of the density.

All other properties, such as particle hardness, compressive strength, young modulus (elastic modulus), all depend mainly on the density values for their structural association with these properties. The hardness values showed a significant improvement and a significant increase in the values of nanocomposites compared to the base material (polymer). The reason is due to the cohesion between the molecules, the substances formed for the compounds, as well as the reason due to the high density possessed by the nanocomposite, and this is shown by Figure (1) of the hardness.

An important test for studying the physical properties is calculating the durability of compression, which is very similar in the mechanism for measuring hardness. The results of compression durability show a clear improvement in the durability values of the compounds compared to the base material. The reason is due to the nanomaterial in transferring stress and distributing it in a way that reduces the failure in the model and this is clearly evident in the figure (compression strength). In Figure 1 of the modulus of elasticity, the great improvement in the values of the modulus of elasticity is evident. This indicates the resistance of the material to compression to a certain extent without any breakdown or collapse. All these properties are consistent with the source ${ }^{[16]}$. 

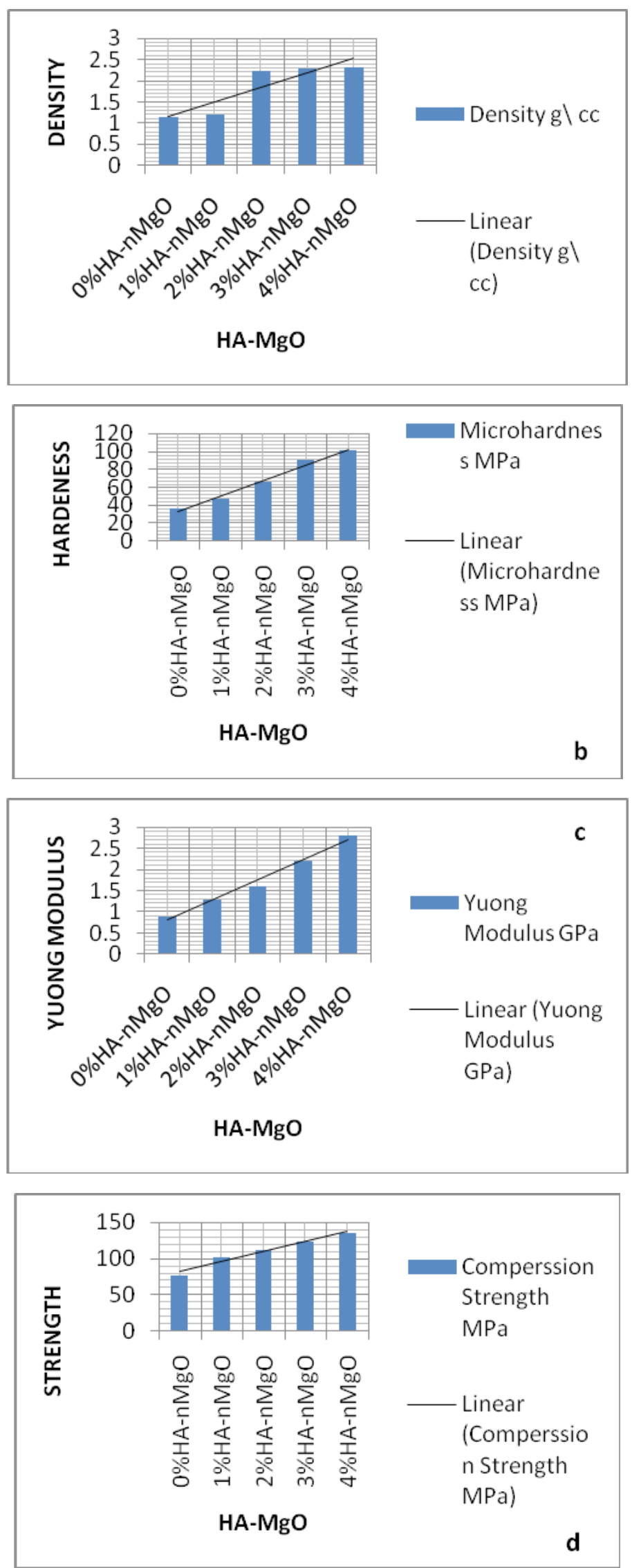

Fig.(1): Experimental of Mechanical Properties (a) Density, (b) Hardiness, (c) young modulus, and (d) compassion with Wight percentage HA-MgO. 
Table (1): Practical results of the physical properties of Nano-composites PMMA $\backslash$ HA-nMgO

\begin{tabular}{|c|c|c|c|c|}
\hline Samples & Density $\mathbf{g} \backslash \mathbf{c m}^{3}$ & Micro-Hardness MPa & Compression Strength MPa & Modulus - Elastic GPa \\
\hline PMMA $\backslash 0 \%$ HAMgO & 1.144 & 36.2 & 77.4 & 0.877 \\
\hline PMMA $\ \%$ HAMgO & 1.198 & 46.9 & 102.4 & 1.3 \\
\hline PMMA $2 \% \mathrm{HAMgO}$ & 2.22 & 65.5 & 111.5 & 1.6 \\
\hline PMMA $13 \% \mathrm{HAMgO}$ & 2.28 & 89.7 & 122.6 & 2.2 \\
\hline PMMA $\backslash 4 \% \mathrm{HAMgO}$ & 2.32 & 100.5 & 135.3 & 2.8 \\
\hline
\end{tabular}

Discuss the wear Rate properties: Table 2 and Figure (2.3) show a summary of the practical results of the triple properties of the prepared samples. A screwon-disk device was used to calculate the dry mechanical corrosion rate of the nanocomposites and the dominant model. The results showed the calculation of the dry sliding wear factor and a clear decrease in the amount of skimming of the nanocomposites. This is due to the improvement of the outer surface of the samples supported by the Nano powder, which led to blocking the pores and voids and strengthening the bonds between the components of the supported sample compared to the unsupported substance (polymer). Therefore, such a work can be used in the dental industry and damaged bone compensation, because these prepared nanocomposites have a high resistance to wear and wear, and this is consistent with the source.

In order to check the practical results of calculating the dry mechanical corrosion rate, the volumetric wear rate was calculated to ensure the accuracy of the calculation. It was included in the calculation of the mechanical corrosion rate, the practical intensity of the prepared models. Figure 3 shows volumetric wear behavior and we note the significant decrease in the volumetric corrosion values of nanocomposites compared to the base material (Polymer).

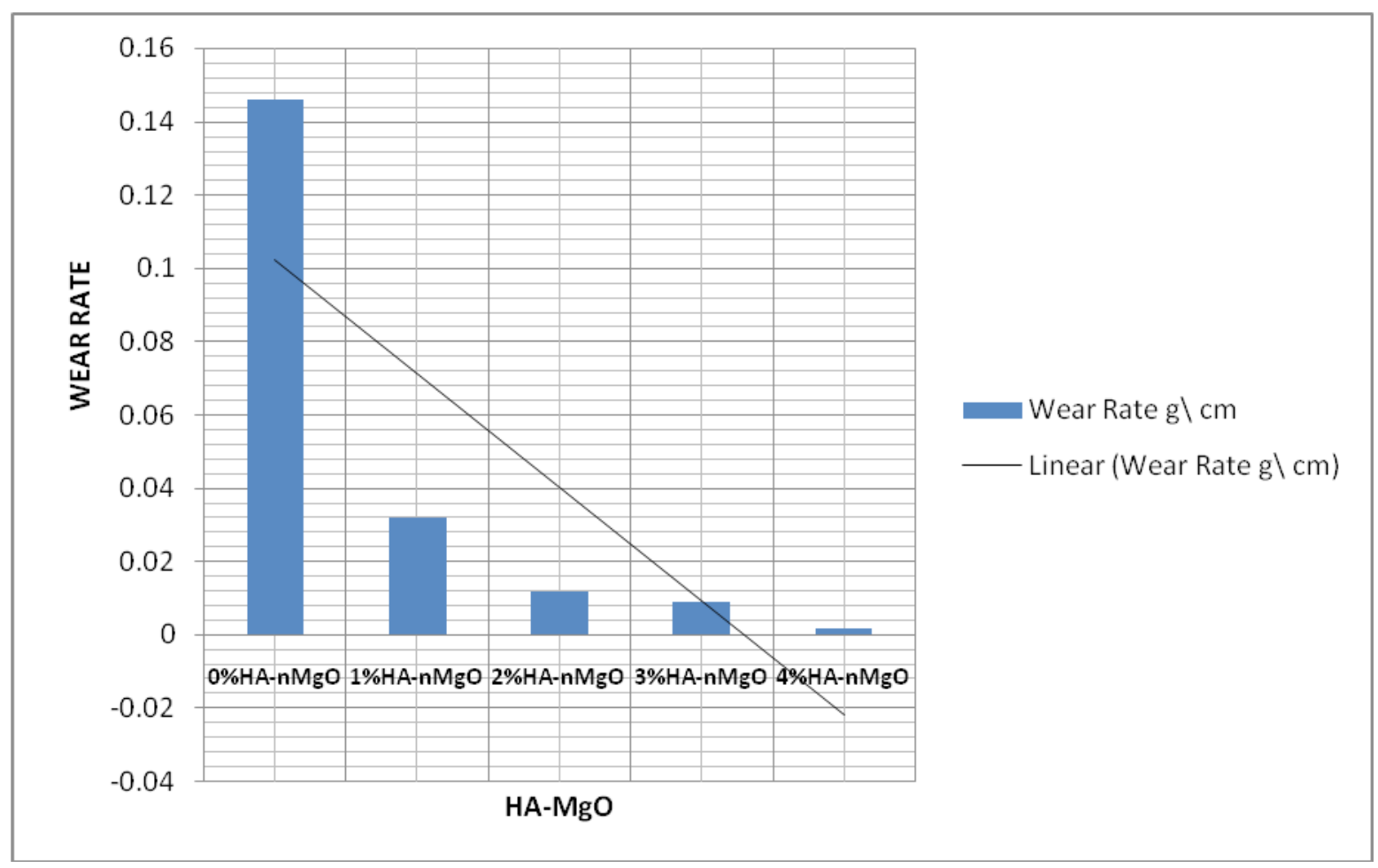

Fig.(2): Experimental Wear Rate with Wight percentage HA-MgO 


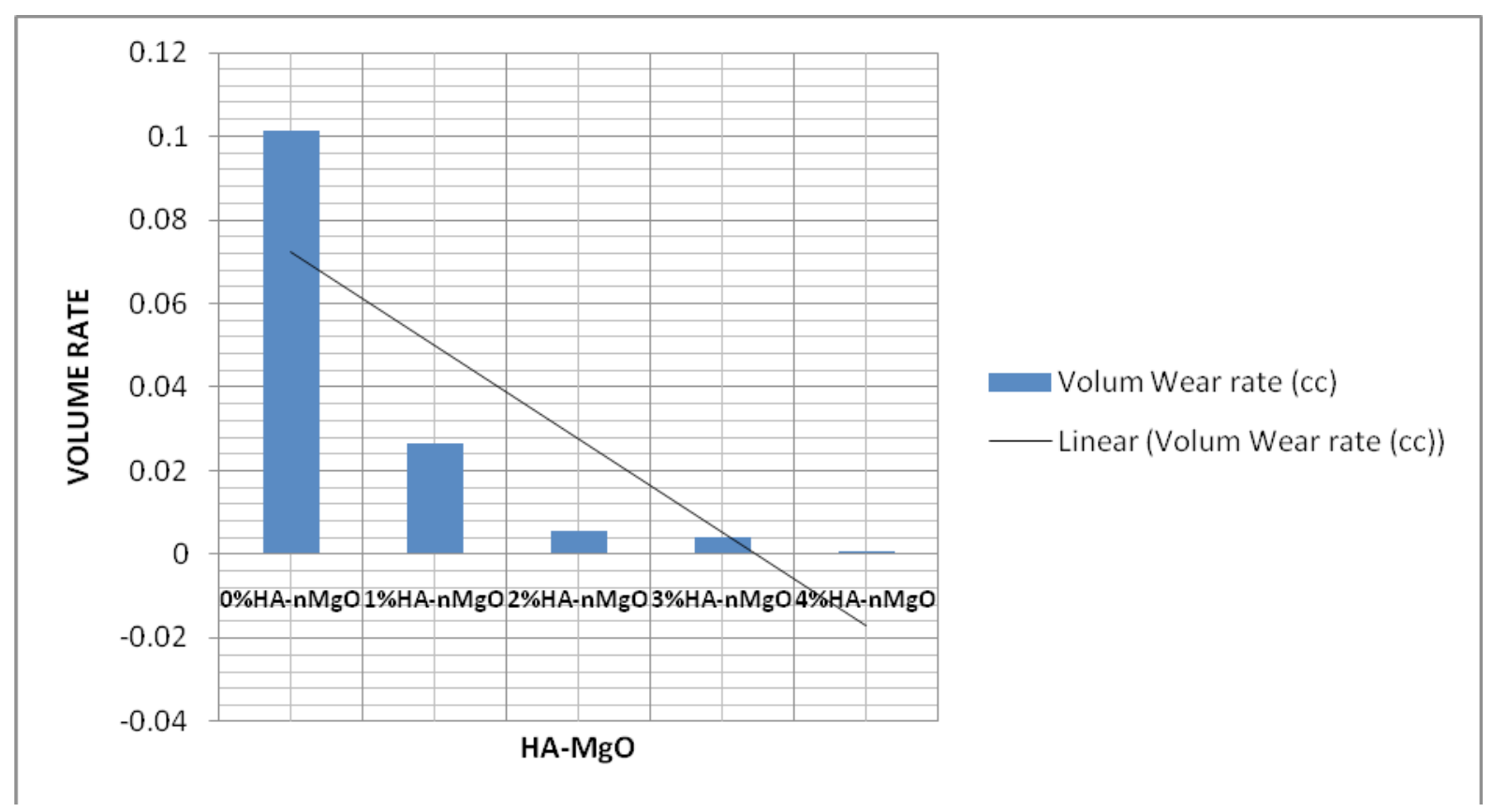

Fig.(3): Experimental Volume Wear Rate with Wight percentage HA-MgO

Table (2): Wear rate at $10 \mathrm{~min}$

\begin{tabular}{|c|c|c|c|c|}
\hline Sample & Mass before wear (g) & Mass After wear (g) & Wear Rate $(\mathrm{g} \backslash \mathrm{cm})^{\wedge} 10^{-5}$ & Volume Wear^10 $0^{-6} \mathrm{~cm}^{3}$ \\
\hline $0 \% \mathrm{HA}-\mathrm{nMgO}$ & 3.246 & 3.100 & 0.146 & 0.10138 \\
\hline $1 \% \mathrm{HA}-\mathrm{nMgO}$ & 3.677 & 3.645 & 0.032 & 0.02671 \\
\hline 2\%HA-nMgO & 3.886 & 3.874 & 0.012 & 0.00545 \\
\hline 3\%HA-nMgO & 3.998 & 3.989 & 0.009 & 0.00394 \\
\hline 4\%HA-nMgO & 4.125 & 4.123 & 0.002 & 0.00086 \\
\hline
\end{tabular}

Discuss the results of the scanning electron microscope: Figure (4) shows pictures of the powders forming the $\mathrm{HA}-\mathrm{MgO}$ compound. Figure (4) a shows the hexa-structure of the hydroxybite with a nanoscale of $20 \mathrm{~nm}$. Figure (4) b shows the fibrous and spindle

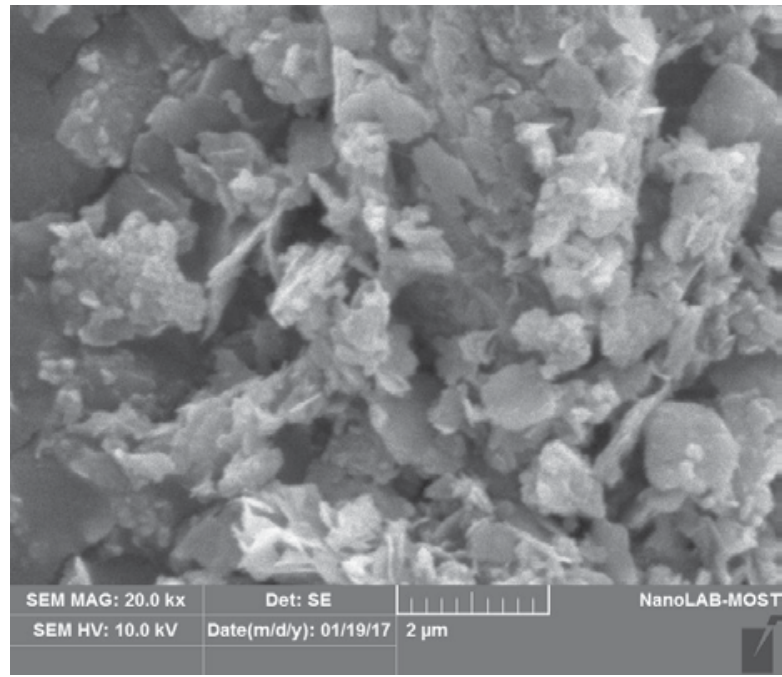

composition of the nano-magnesium oxide compound, while Figure 4 (c) shows the mixed composition of the two compounds to form a non-distinct homogeneous compound.

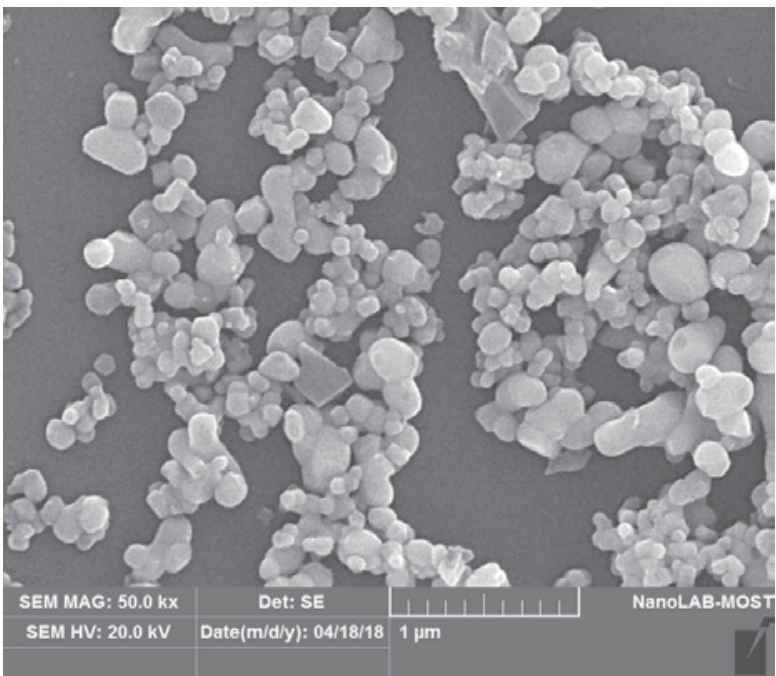




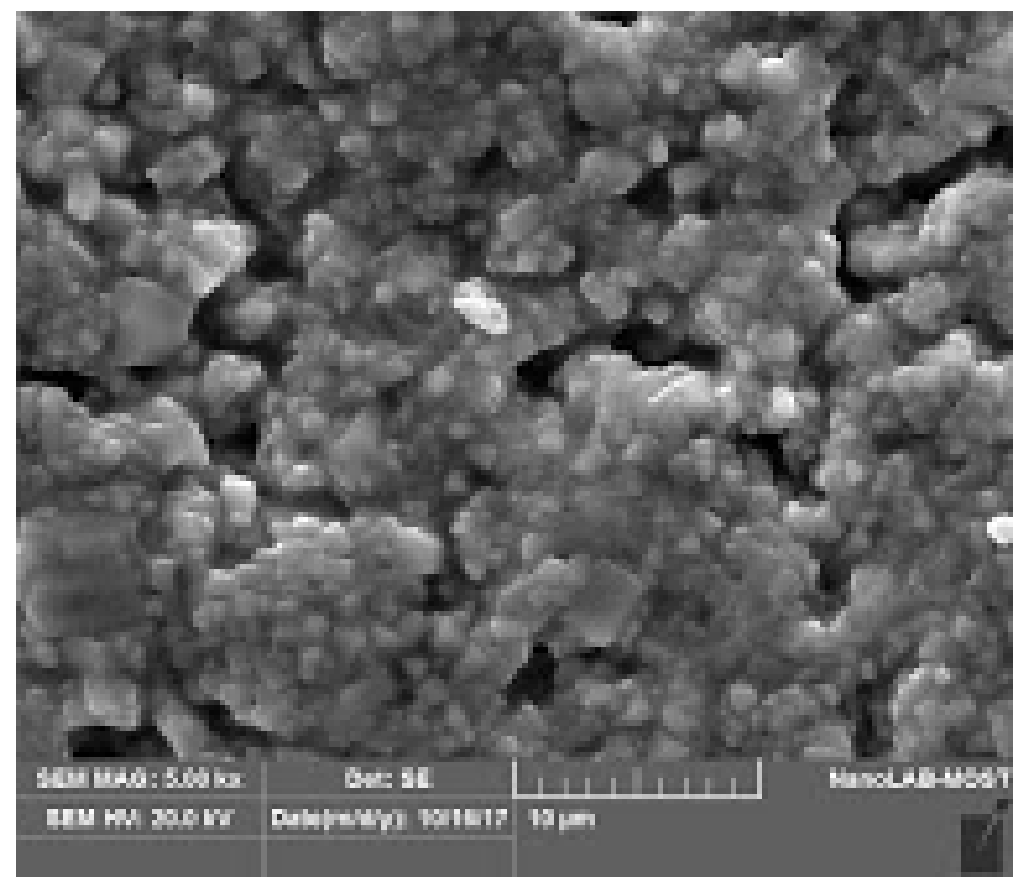

Fig. (4): SEM-Images of (a) HA, (b) MgO, and (c) HA-MgO

\section{Conclusions}

We conclude from the above from the current research:

1. The significant improvement in all the physical properties of the nanocomposites is due to the great correlation between the nanocomposite within the polymer molecules, which gives it strength, durability, hardness and an increase in stacking.

2. The significant decrease in the scaling amount of nanocomposites to rates that do not nearly affect the weight and size of the samples is due to the high surface area of the nanocomposite and to the nanoscale used.

3. Scanning electron microscopy images show the shape and size of the compounds involved in the final compound composition, and through them the result was explained in $(1,2)$ in addition to the density values.

Ethical Clearance: This study was approved by the Ethics Committee, University of Karkh for Science. The study protocol was thoroughly explained for using samples of patients and written informed consents were obtained from them prior to participation in the study.

\section{Source of Funding: By Self}

\section{Conflict of Interest: Nil}

\section{References}

1. Patel RR, Kishorekumar B, Gupta N. Effect of filler materials and pre-processing techniques on conduction processes in epoxy-based nanodielectrics. In 2009 IEEE Electrical Insulation Conference 2009 May 31 (pp. 392-396). IEEE.

2. Suresha B. The role of fillers on friction and slide wear characteristics in glass-epoxy composite systems. Journal of Minerals and Materials Characterization and Engineering. 2006 Jun 12;5(01):87.

3. Jabbar A, Nayyef S. Studying mechanical and physical properties for polymer composite material reinforced by metal powders, Baghdad, 2008.

4. Dawood JJ. A Comparison Between the Wear Rate Behavior of Polyester Reinforced by Glass and Kevlar Fibers. Engineering and Technology Journal. 2009;27(11):2273-85.

5. Sun H, He S, Wu P, Gao C, Feng P, Xiao T, Deng Y, Shuai C. A novel MgO-CaO-SiO2 system for fabricating bone scaffolds with improved overall performance. Materials. 2016 Apr;9(4):287.

6. Tan TY, Kennedy BJ, Zhou Q, Ling CD, Miiller W, Howard CJ, Carpenter MA, Knight KS. Impact 
of Jahn-Teller active Mn 3+ on strain effects and phase transitions in $\mathrm{Sr} 0.65 \operatorname{Pr} 0.35 \mathrm{MnO}$ 3. Physical Review B. 2012 Mar 19;85(10):104107.

7. Farhan FK, Kadhim MO, Ashour SJ. Preparation and Development of Ceramic System CaTiO3 for Used Medical Applications. Journal of Computational and Theoretical Nanoscience. 2019 Jan 1;16(1):109-14.

8. Kurella A, Dahotre NB. Surface modification for bioimplants: the role of laser surface engineering. Journal of biomaterials applications. 2005 Jul;20(1):5-0.

9. Kharaziha M, Fathi MH. Synthesis and characterization of bioactive forsterite nanopowder. Ceramics international. 2009 Aug 1;35(6):2449-54.

10. Khang D, Lu J, Yao C, Haberstroh KM, Webster TJ. The role of nanometer and sub-micron surface features on vascular and bone cell adhesion on titanium. Biomaterials. 2008 Mar 1;29(8):970-83.

11. Liu Q, Cen L, Yin S, Chen L, Liu G, Chang J, Cui L. A comparative study of proliferation and osteogenic differentiation of adipose-derived stem cells on akermanite and $\beta$-TCP ceramics. Biomaterials. 2008 Dec 1;29(36):4792-9.

12. Alwan SA, Alameer SS. The effect of the addition of silanized Nano titania fillers on some physical and mechanical properties of heat cured acrylic denture base materials. Journal of Baghdad College of Dentistry. 2015 Mar;325(2218):1-2.

13. Thandavamoorthy TS. Determination of concrete compressive strength: A novel approach. Advances in Applied Science Research. 2015;6(10):88-96.

14. Farhan FK, Kadhim MO, Ashour SJ. Preparation and Development of Ceramic System CaTiO3 for Used Medical Applications. Journal of Computational and Theoretical Nanoscience. 2019 Jan 1;16(1):109-14.

15. ASTMStandardDesignation G 99-95a (Reapproved 2000). Standard test method for wear testing with a pin-on-disk apparatus. Metals test method and analytical procedures 03.02. 2002:414-9. 